\title{
Numerical Analysis on Temperature Rise of a Concrete Arch Dam after Sealing Based on Measured Data
}

\author{
Qingbin Li, Guohe Liang, Yu Hu, and Zheng Zuo \\ Department of Hydraulic Engineering, State Key Laboratory of Hydroscience and Engineering, Tsinghua University, \\ Beijing 100084, China \\ Correspondence should be addressed to Yu Hu; yu-hu@tsinghua.edu.cn
}

Received 27 December 2013; Accepted 4 February 2014; Published 9 April 2014

Academic Editor: Fei Kang

Copyright (C) 2014 Qingbin Li et al. This is an open access article distributed under the Creative Commons Attribution License, which permits unrestricted use, distribution, and reproduction in any medium, provided the original work is properly cited.

The thermal boundary conditions in the construction and operation phases of a concrete arch dam are always complex. After sealing, differences between the arch dam temperature and its sealing temperature can cause compressive or tensile stresses. Based on measured temperature of an arch dam located in China, a temperature rise phenomenon (TRP) is found in the after-sealed regions of the arch dam. By mining and analyzing the temperature data of various monitoring apparatus embedded in the arch dam, higher environment temperature is considered to be the main cause for the occurrence of the TRP. Mathematical methods for complex thermal boundary conditions, including external boundary conditions and internal heat source conditions, are proposed in this paper. A finite element model is implemented with the concern of the construction phase and operation phase of the arch dam. Results confirm good agreement with the measured temperature and verify the conjecture that the TRP occurs mainly because the external temperature of the arch dam is higher than its sealing temperature.

\section{Introduction}

Thermal effects have frequently been associated with the damage to concrete structures, particularly to massive concrete structures such as concrete bridges and dams. Temperature in concrete dams can affect creep and alkali aggregate reaction and has direct effects on the thermoelastic properties of concrete. Therefore, temperature variation and the associated thermal stresses must be evaluated to define loading conditions for development of a defensive measure in dam safety analysis.

Temperature effects on arch dams can be studied in two distinct phases: construction and operation [1]. In the construction phase, the temperature field of a concrete arch dam is subjected to variation of ambient temperature, solar radiations variation, hydration reaction of cement, and water cooling of cooling pipes. In the operation phase, the temperature field of a concrete arch dam is subjected to the ambient temperature and reservoir temperature variations as well as solar radiation variations. The arch dams are always sealed by layer during the construction phase. Before sealing, temperature of concrete is reduced to sealing temperature to open the transverse joints. After sealing the dam is considered to be a continuous system, consequently differences between temperature of the arch dam and the sealing temperature can cause compressive or tensile stresses [2].

Leger et al. [3, 4] proposed a numerical two-dimensional (2D) model to calculate the temperature field in a concrete gravity dam during its operation period. They found that the temperature gradient near the exposed surface of the dam generates tensile stresses, which can cause surface cracks. Agullo and Aguado [5] presented an analytical model for the simulation of the thermal behaviour of dams that are subjected to environmental thermal action during operation. They found that the mean temperature of the section depends on the annual mean ambient temperature, the annual mean temperature of the water, and the annual mean of total daily solar radiation at the site. Zhang and Garga [6] found that the highest temperature and temperature gradient are induced in a very thin region close to the exposed surface, and the stress concentration can be reduced by changing the property of concrete and the heat transfer coefficient as a curing condition. Daoud et al. [7] described a numerical analysis of the periodic temperature field in a concrete gravity dam. 
They considered ambient temperature variation, solar radiation, snow cover, geothermal gradient, and ice formation in the reservoir water as well as different conductivities for saturated and unsaturated parts of the dam. Sheibany and Ghaemian [2] intensively studied the environmental effect of heat transfer in arch dam engineering. They observed that thermal loads have the most significant effects that induce the occurrence of downstream cracks compared with selfweight and hydrostatic loads. Jin et al. [8] investigated the solar effect on exposed dam surfaces during the operation phase. A practical model for predicting the nonuniform temperature of the exposed face is presented by considering both solar radiation and shading effects in the paper. However, the objects of these studies were dams that had already been built; that is, the dams were already under the operation phase, where the situation of the external surface boundary regions barely changes. Temperature variations after sealing of the arch dams were not discussed in the above studies.

Kuzmanovic et al. [9], based on 2D and three-dimensional (3D) numerical models, described an unsteady phased thermal analysis of roller compacted concrete (RCC) gravity dams. A long-term modeling study taking both construction phase and operation phase into account was considered and a parametric study was proposed. They found that the 2D model accurately describes the RCC dam thermal field and the thermal properties of the mixture and the boundary conditions have the greatest influence on the thermal behavior of RCC dams. However, the sealing process was not designed in the RCC gravity dam and water temperature in the reservoir was simplified as constant.

In the dam-foundation-reservoir system, the foundation of the arch dam can be mathematically treated as an infinite domain, compared with the size of an arch dam $[10,11]$. However, conventional finite element method can be only used to effectively simulate the problem of a finite domain. To overcome this difficulty, Zhao and Valliappan [12] developed transient infinite elements for simulating transient heat transfer in infinite media. This means that the coupled method of finite elements and transient infinite elements is already available for simulating transient heat transfer process in an arch dam foundation. However, due to the limitation of our current computer code, the infinite extension of the arch dam is approximately truncated as a finite domain so that the conventional finite element method can be used in this study.

In this paper, we focus on a long-term temperature rise phenomenon (TRP) in the after-sealed regions of the Xiluodu concrete arch dam, which also occurred in several other similar dams. This phenomenon can affect the stress field and safety of the arch dams, but few studies have been conducted to access the situation and predict development pattern of the TRP. After analyzing measured temperature of the arch dam, a higher environment temperature is considered to be the most possible cause for the TRP. Real thermal boundary conditions are studied and a numerical model taking both construction phase and operation phase of the arch dam into account is presented to verify our conjecture.

\section{TRP Based on Measured Data}

Xiluodu arch dam is located in the lower reach of the Jinsha River, Yunnan Province, in Southwest China. The project is designed as a dome dam with a maximum height of $285.5 \mathrm{~m}$ and a crest length of $700 \mathrm{~m}$. The footing sits upon the riverbed foundation on a $324.5 \mathrm{~m}$ elevation. The arch dam body is designed with seven $12.5 \mathrm{~m} \times 13.5 \mathrm{~m}$ surface spillways and eight $6 \mathrm{~m} \times 6.7 \mathrm{~m}$ deep outlet holes. Thirty-one monoliths are planted across the river. The transversal section of the dam is curve-shaped and is $14 \mathrm{~m}$ wide at the crest and $60 \mathrm{~m}$ wide at the footing. The dam started casting concrete on March 2009 and the reservoir was impounded on March 2012 while the dam was still under construction. The arch dam seals the joint layer by layer and starts cooling the sealed regions before the sealing time. The first sealed region of the arch dam was sealed on August 2010.

Various electrical equipments have been embedded in the arch dam and its foundation to monitor its working condition, including thermometer, strain meter, nonstress meter, and joint meter (see Figure 1). Not only do the thermometers measure the temperature of concrete, but also the other electrical equipment to eliminate the effect of thermal expansion. Figure 2 shows typical temperature history of the arch dam, the data of which is from thermometers and joint meters embedded in the concrete of the first sealed region and the foundation. Obvious TRP occurs in the concrete of the dam after sealing through the measured data. The deep foundation appears to have a stable temperature field, relative to a high temperature of nearly $25.6^{\circ} \mathrm{C}$.

To observe the global temperature rise situation of the arch dam, temperature data of various monitoring apparatus were mined and analyzed. We grouped monitoring apparatus by sealed region as the TRP occurred right after sealing, same sealed regions had the same sealing time and higher sealed regions were sealed after the lower regions. Average amplitudes of temperature rise until July 2013 after sealing at different sealed regions are shown in Figure 3, including the locations of galleries and outlets of the arch dam. Several sealed regions do not have enough measured data, and their situations are marked as empty in the figure. General sealing temperature of the arch dam is $12^{\circ} \mathrm{C}$ to $13^{\circ} \mathrm{C}$ and amplitudes of temperature rise in higher sealed regions are generally smaller than the lower regions. The amplitudes of temperature rise in the first two sealed regions are the biggest at an average of $7.7^{\circ} \mathrm{C}$, which is nearly two times bigger than the fourth sealed region. We also observed that sealed regions with galleries or outlet holes have relativly bigger amplitudes of temperature rise.

Determining the cause for the TRP is important and necessary. Higher environment temperature is the most possible cause for the occurrence of the TRP. The mean annual temperature of the Xiluodu dam site is $20^{\circ} \mathrm{C}$ and the mean temperature of deep foundation is approximately $25.6^{\circ} \mathrm{C}, 7^{\circ} \mathrm{C}$, and $12^{\circ} \mathrm{C}$ higher than the sealing temperature of the arch dam, respectively. This higher environment temperature explains why the concrete close to the riverbed foundation, galleries, and outlets have rather bigger amplitudes. If this is true, the temperature field of the arch dam would rise matching 


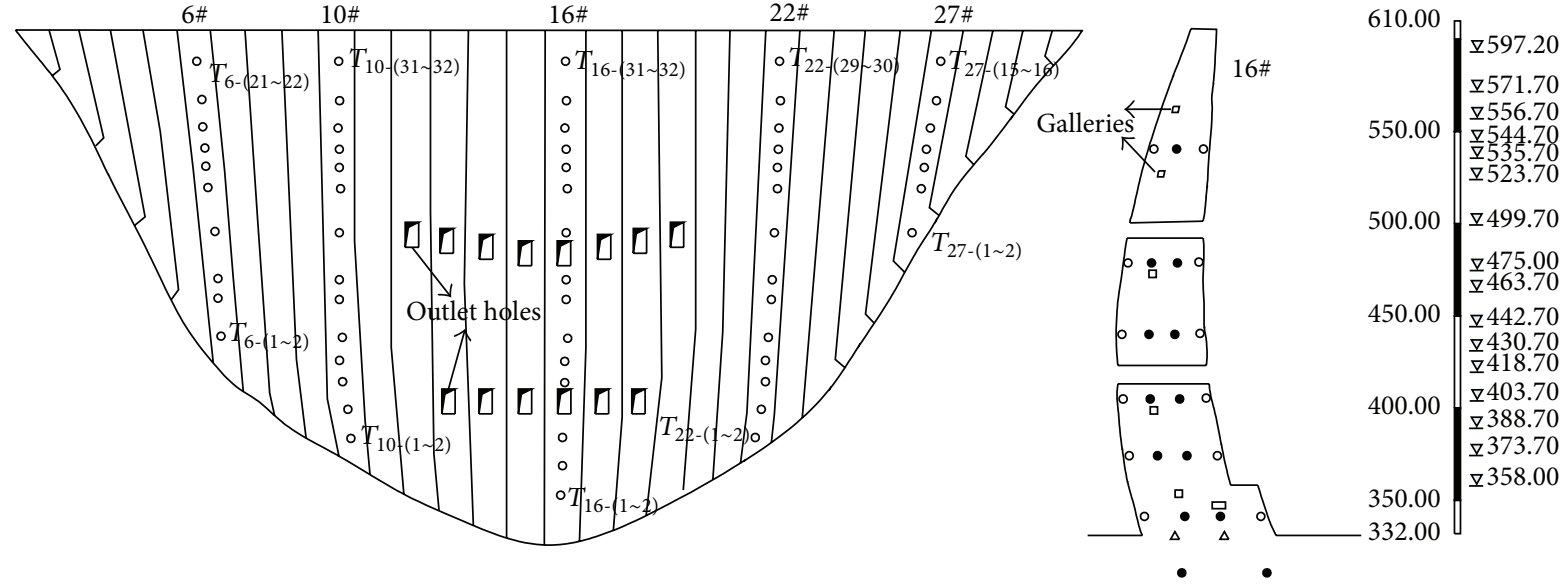

- Thermometers

- Strain meters

$\Delta$ Joint meters

FIGURE 1: Instruments setup.

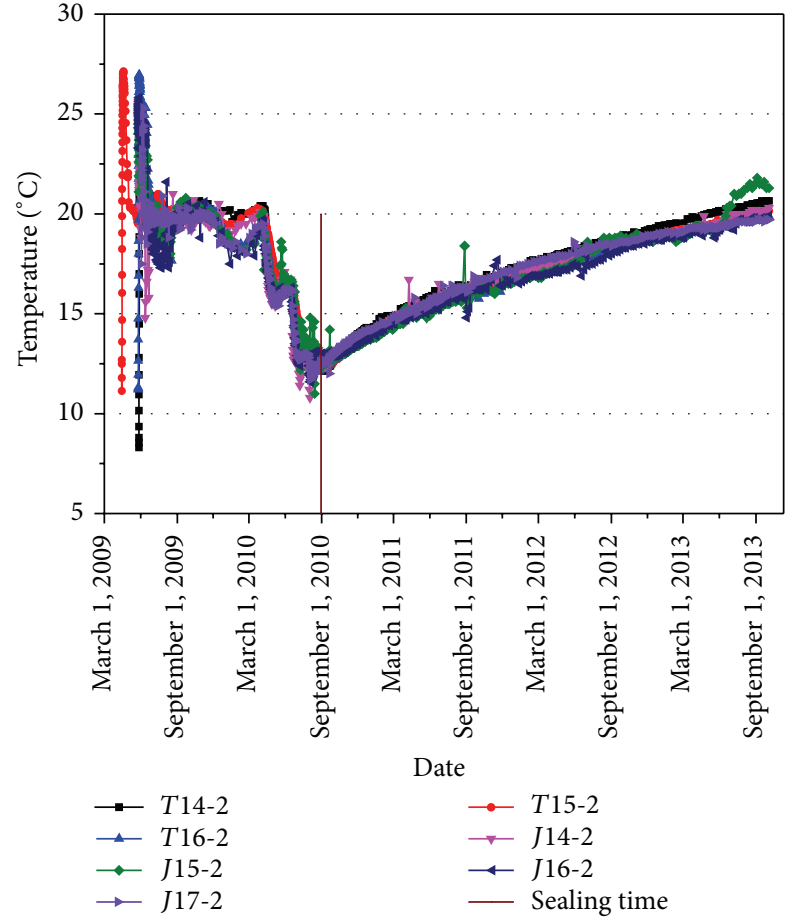

(a) Temperature history in concrete of first sealed region

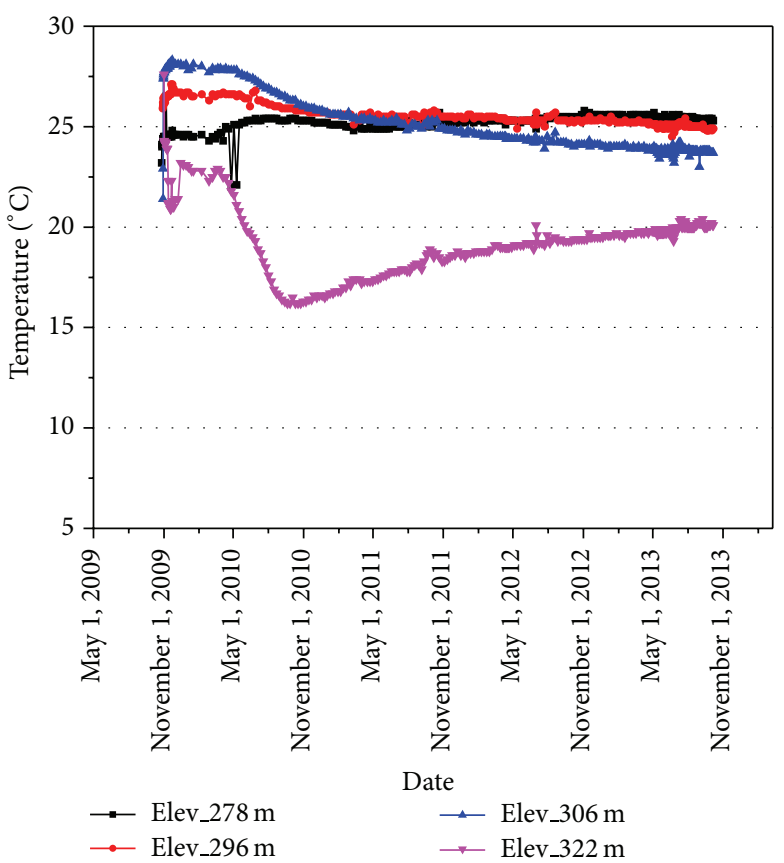

(b) Temperature history in foundation of different elevations

FIGURE 2: Typical temperature development process.

that of the environment and then stabilizes. However, this conjecture requires verification in numerical model with real thermal boundary conditions taking both construction and operation phase into account. Section 3 proposed methods to study real thermal boundary conditions of arch dam, and Section 5 provides verification of this numerical model, which is implemented based on the measured temperature data of the arch dam.

\section{Real Thermal Boundary Conditions}

As discussed in Section 1, temperature effects on arch dams can be studied in construction phase and operation phase. One of the significant differences between thermal boundary conditions in the two phases is that during the construction phase there is internal hydration heat and cooling effect of cooling pipes. In addition, the upstream air-side surface 


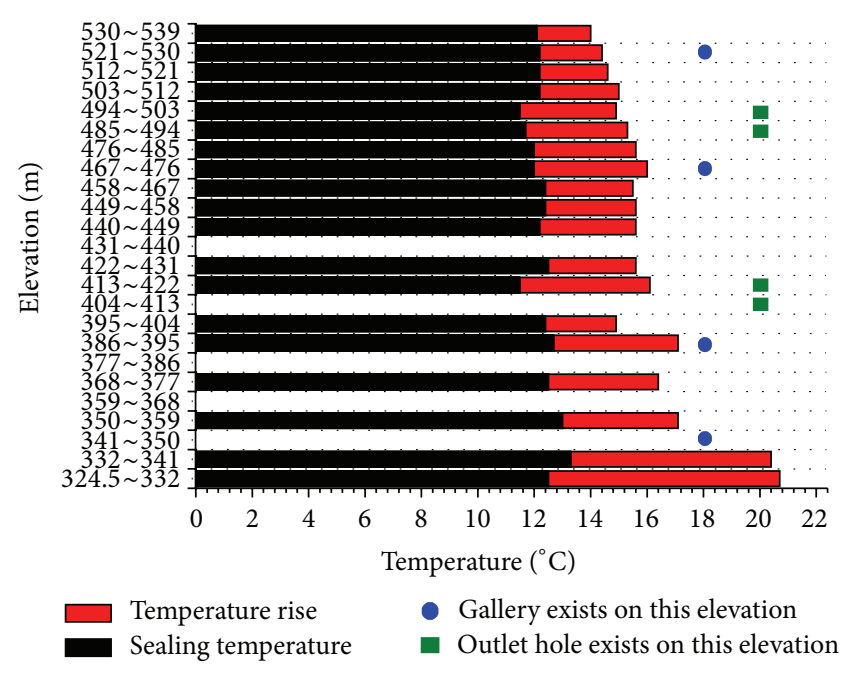

FIgURE 3: Average amplitudes of temperature rise after sealing at different sealed regions.

changes to become water-side surface when the reservoir is impounded. Figure 4 shows the thermal boundary conditions adopted in this study. Mathematical methods to describe thermal boundary conditions with various influencing factors are proposed in this section.

\subsection{External Boundary Conditions}

3.1.1. Concrete-Air Interface. The heat transfer between the dam and the air boundary layer is a function of air and concrete temperatures, wind speed, and solar radiation intensity [3]. Therefore, boundary conditions including heat convection, absorbed radiation from the sun, and electromagnetic radiation should be considered at the concrete-air interface.

The air-side convective flux $q_{a}$ is proportional to the temperature difference between the concrete and the surrounding air. Heat convection can be given by Newton's law of cooling:

$$
q_{a}=\beta_{a}\left(T-T_{a}\right),
$$

where $T$ is the temperature of the surface; $T_{a}$ is the temperature of surrounding air; $\beta_{a}$ is the convective coefficient, which is considered constant in some previous studies on dams $[8,13,14]$. However, the convective coefficient is actually affected by numerous factors, among which wind speed was highlighted in recent studies as the major factor $[15,16]$. As arch dams are usually built in canyons where wind is naturally strong, the wind effect on convective coefficient should be considered in the thermal simulation of arch dams. NusseltJürges correlation [15], a well-established form of convective coefficient that considers wind speed, is used in this paper and can be defined as

$$
\beta_{a}=5.678\left\{a+b\left[\left(\frac{294.26}{T_{a}}\right) \frac{w}{0.3048}\right]^{m}\right\},
$$

where $w$ is the wind speed; $a, b$, and $m$ are the parameters to be decided based on the applied condition. $T_{a}$ is the ambient temperature (in Kelvin). The amount by which the surface temperature lags behind the air temperature depends on the convection coefficient. The surface temperature will follow the air temperature exactly when a large convection coefficient $\left(\beta_{a}=10^{10}\right)$ is used [17].

Solar radiation was not considered in numerous thermal studies on dams $[13,14,18]$ because proper calculation of the absorbed solar radiation of the structure surface is complex, which must consider the sun position, environmental factors, and surface conditions. However, solar radiation is an important source of energy to reach the surface of the dam not covered by water. A recent work [8] showed that irradiation has a great thermal effect on the exposed surfaces of a dam. The total solar radiation $E_{s}$ reaching a surface comprises three components including beam radiation, sky diffuse radiation, and ground diffuse radiation. Beam radiation $E_{\text {beam }}$ reaches the face of the dam directly from the sun. Sky diffuse radiation $E_{\text {diff }}$ is the solar radiation that reaches the dam surface after its direction has been scattered by the atmosphere. Ground diffuse radiation $E_{\text {refl }}$ is the solar radiation reflected by the ground. Based on the above absorbed solar radiation by the surface, $q_{s}$ can be expressed as

$$
\begin{gathered}
q_{s}=\alpha E_{s}, \\
E_{s}=\alpha_{\text {beam }} E_{\text {beam }}+\alpha_{\text {diff }} E_{\text {diff }}+E_{\text {refl }},
\end{gathered}
$$

where $\alpha$ is the solar absorptivity of the surface; $\alpha_{\text {beam }}$ and $\alpha_{\text {diff }}$ denote the irradiation coefficient, considering the surface angle. These components can be obtained through mathematical and geometry relations with the extraterrestrial solar radiation from a clear-sky model proposed by ASHRAE [19]. Solar radiation input occurs only during daytime with a clear sky. $q_{s}$ is small during night and rainy days and can be neglected. In engineering applications, the daily energy can be summed up based on the hourly $E_{s}$ value:

$$
q_{s}(D)=\alpha \sum_{H=H_{\text {Rise }}}^{H_{\text {Set }}-H_{\text {Rise }}} E_{s}(H)=\alpha \overline{E_{s}}\left(H_{\text {Set }}-H_{\text {Rise }}\right),
$$

where $D$ is the day of year; $H_{\text {Rise }}$ and $H_{\text {Set }}$ denote the sunrise and sunset hours, respectively; and $\overline{E_{\text {Sun }}}$ denotes the time average value of $E_{\text {Sun }}$ during daytime [20].

Electromagnetic radiation is released from the exposed surface of the dam due to temperature differences between the surface and the air. This radiation can be calculated using the Stefan-Boltzman law:

$$
q_{r}=e C_{s}\left(T^{4}-T_{a}^{4}\right),
$$

where $e$ is the emissivity of the surface, also named as blackness, ranging from 0 to $1 ; C_{s}=5.669 \times 10^{-8} \mathrm{Wm}^{-2} \mathrm{~K}^{-4}$, which is referred to as the Stefan-Boltzmann constant [21]. The temperatures applied in (5) should notably be used in degrees Kelvin.

3.1.2. Concrete-Water Interface. When the reservoir impounds, the upstream concrete-air interface under water level will change to concrete-water interface. This convection 


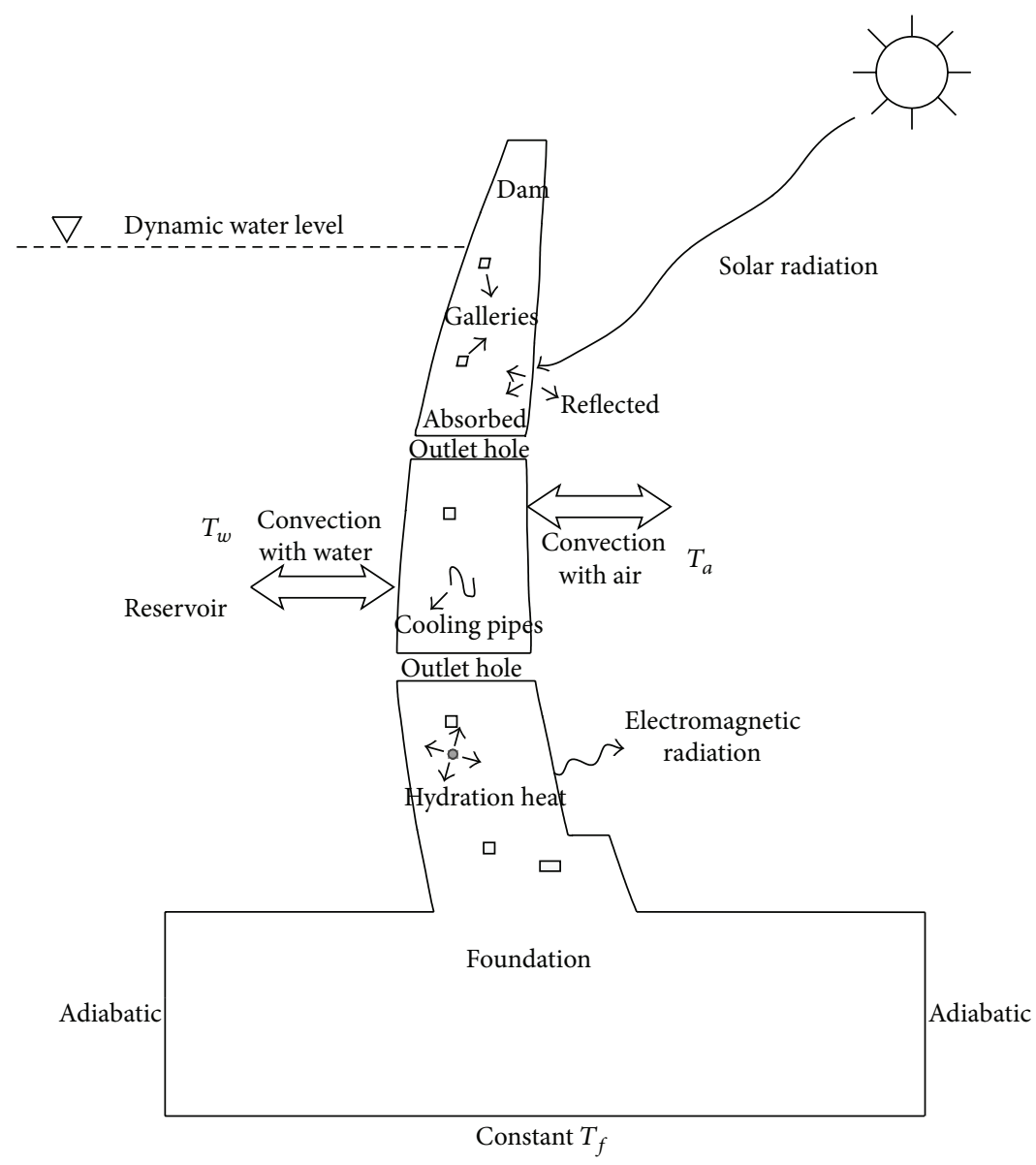

FIgURE 4: Thermal boundary conditions for an arch dam.

boundary with liquid fluid can also be described by Newton's law of cooling:

$$
q_{w}=\beta_{w}\left(T-T_{w}\right),
$$

where $T$ is the temperature of the surface; $T_{w}$ is the water temperature; and $\beta_{w}$ is the convective coefficient. Coefficient $\beta_{w}$ is relatively large for water-side convection in contrast to air-side convection. The water-side convection coefficient is 20 to 1,000 times that of the air-side convection $[22,23]$. In this situation, the boundary can also be dealt with as first-type boundary condition:

$$
T=T_{w},
$$

where $T_{w}$ can be obtained by monitoring the water temperature or through empirical prediction method [24, 25]. However, several dams begin to fill the reservoir during the construction phase to improve the performance of power production. Thermometer to monitor the water temperature of the reservoir may not be set as an urgent casting schedule of the dam. The empirical method is only suitable for the reservoir in operation phase when a relative stable temperature field has formed. The water level of the reservoir rises rapidly during the first impoundment and water temperature of the upper reach has a significant effect on the reservoir temperature field. Meanwhile heat transfer exits between reservoir water and the rock foundation as high ground temperature shown in Figure 1. Based on the above conditions, we propose an interpolation equation considering both ground temperature and water temperature of the upper reach:

$$
T_{w}(h, \tau)=\left[1-\left(\frac{h}{H(\tau)}\right)^{\eta}\right] T_{g}+\left(\frac{h}{H(\tau)}\right)^{\eta} T_{r}
$$

where $h$ denotes height to reservoir bottom; $H(\tau)$ denotes water depth on time $\tau$; $T_{g}$ denotes ground temperature; $T_{r}$ denotes water temperature of the upper reach of the river; and $\eta$ denotes environmental parameter. $T_{r}$ can be obtained through measured hydrological data of a river or calculated by meteorological data [26].

Transformation of boundary conditions from first-type to second-type is difficult to achieve in a numerical model during its calculating process. Since a long-term simulation of the arch dam including the impounding process of the reservoir is considered, the concrete-water interface is dealt with as a convection boundary in this paper.

3.1.3. Concrete-Insulation Interface. The concrete surface may be covered with insulation protections during construction 


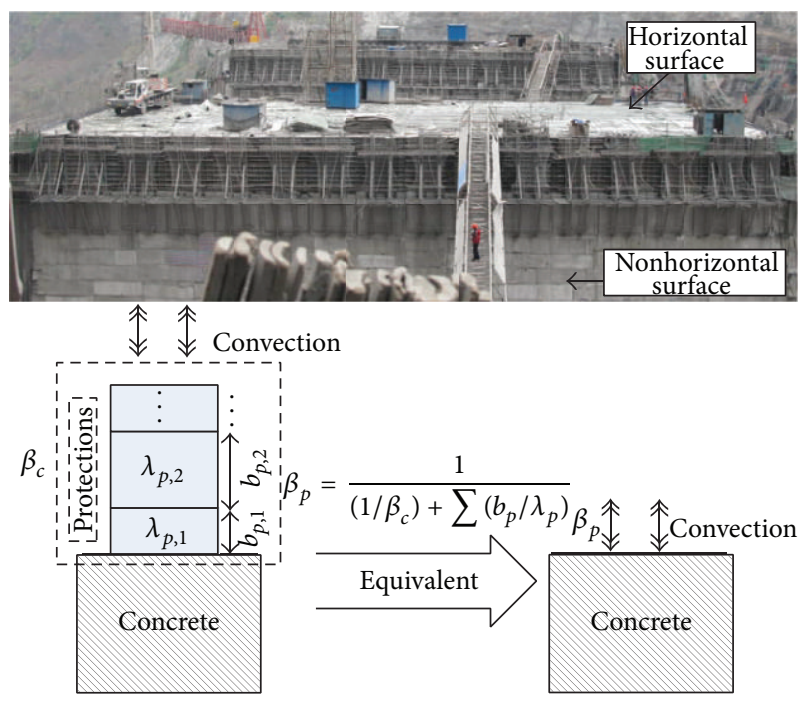

FIGURE 5: Surface protection and its equivalent model.

to prevent thermal cracks induced by atmospheric temperature shock. Materials with high thermal resistances, such as cotton quilts, polystyrene foam plastic boards, and sprayed polyurethane, are ideal options for protection in engineering applications. Figure 5 shows two typical thermal protections used in dams. Tiling the cotton quilt on horizontal surfaces, such as the top faces of new-cast lifts, is convenient, and polystyrene foam boards are suitable for pasting clung to the nonhorizontal surfaces. We can consider the boundary condition as a composite wall comprising miscellaneous materials in a series. Similar to the air-side convection, we can apply the following Robin boundary condition:

$$
q_{p}=\beta_{p}\left(T-T_{a}\right)
$$

where $\beta_{p}$ denotes the equivalent convection coefficient of the protection series and is expressed as the reciprocal of the sum of thermal resistances:

$$
\beta_{p}=\frac{1}{1 / \beta_{c}+\sum\left(b_{p} / \lambda_{p}\right)},
$$

where $\beta_{c}$ denotes the nonprotective convective coefficient in a nonwind condition $\left[w=0\right.$ in (2)], $b_{p}$ denotes the width of each protection, and $\lambda_{p}$ denotes the thermal conduction coefficient of each insulation layer.

3.1.4. Concrete-Foundation Interface. In thermal simulation of concrete dam, heat transfer at the concrete-foundation interface is assumed to occur only by conduction. The temperature at the bottom surface of the foundation $T_{f}$ is assumed to be constant

$$
T_{f}=\text { const, }
$$

and thermal boundary condition at the side surfaces of the foundation is defined as the adiabatic side surface.
Note that the use of this dam-foundation interface model means that the detailed heat transfer mechanisms in the foundation were neglected in this study. When the reservoir is impounded, the reservoir water seepage can take place in the arch dam foundation, especially in the upstream direction of the arch dam. As demonstrated by the existing studies $[27,28]$, the resulting seepage flow is fully coupled with heat transfer processes, leading to convective and advective heat transfer in the arch dam foundation. In addition, flow focusing $[29,30]$ and convection may also take place in the large cracks and fault zones [31, 32], if any, within the arch dam foundation, resulting in strong temperature localization of the arch dam foundation. This indicates that the temperature distribution in the arch dam foundation is a complicated phenomenon, so that the coupled model of seepage flow and heat transfer (including conductive, advective, and convective heat transfer), which has been well developed in the emerging computational geoscience [33], should be used to simulate this complicated phenomenon in the future research.

\subsection{Internal Heat Source Conditions}

3.2.1. Hydration Heat. The hydration heat property of concrete can be considered by a mathematic model in thermal simulation of the concrete arch dam. Many types of model describe the relationship between heat release rate of concrete and its age, such as single exponential model, double exponential model, and hyperbolic model. However, not all the models above have considered the low heat release rate of fly ash which has been an important component of cementitious material in massive concrete in recent years. We use a combination exponential model to describe low heat release rate of fly ash concrete:

$$
\theta=\theta_{0}\left[s\left(1-e^{-m_{1} \tau}\right)+(1-s)\left(1-e^{-m_{2} \tau}\right)\right],
$$

where $\theta_{0}$ is adiabatic the temperature rise of concrete, $m_{1}$ and $m_{2}$ are both heat release coefficients, $\tau$ is age of concrete, and $s$ is constant.

3.2.2. Cooling Pipes. Many researchers studied cooling effect of cooling pipe. Zhu [34] proposed a simulation formula to describe cooling effect of pipe

$$
\phi=e^{-k_{1}\left(a^{\prime} \tau / D^{2}\right)^{s}}
$$

where $k_{1}, s$ denote coefficients that are related to thermal properties of concrete, length of pipe, and water flow; $a^{\prime}$ denotes equivalent concrete thermal diffusivity; $\tau$ denotes time; and $D$ denotes diameter of cooling area. When $n(n>1)$ layers of pipes made of different materials are laid in one cast, the following modifier formula is promoted [35]:

$$
\begin{gathered}
\phi=e^{-k_{1}\left(a_{n}^{\prime} \tau / D^{2}\right)^{s}}, \\
a_{n}^{\prime}=\frac{D^{2}}{\tau}\left[\frac{1}{n} \sum_{i=1}^{n}\left(a_{i}^{\prime} \tau / D^{2}\right)^{s}\right]^{1 / s},
\end{gathered}
$$


where $a_{i}^{\prime}$ denotes equivalent concrete thermal diffusivity of the $i$ th layer of cooling pipes.

\section{Numerical Method}

The governing equation of 3D unsteady heat transfer can be derived from the energy conservation principle and the Fourier law of heat conduction, which is written as follows:

$$
\rho C_{p} \frac{\partial T}{\partial \tau}=\left(\lambda_{x} \frac{\partial^{2} T}{\partial x^{2}}+\lambda_{y} \frac{\partial^{2} T}{\partial y^{2}}+\lambda_{z} \frac{\partial^{2} T}{\partial z^{2}}\right)+f
$$

where $\rho$ is the density; $C_{p}$ is the heat capacity; $T$ is the temperature; $\lambda$ is the thermal conductivity, which is always considered isotropic in concrete material; that is, $\lambda=\lambda_{x}=$ $\lambda_{y}=\lambda_{z}$; and $f$ is the internal heat source produced per volume, homogeneously distributed over the concrete. $f$ generally consists of two main parts: hydration heat generation and the cooling effect of embedded cool-pipes as discussed in Section 3.

The external heat transfer of the boundary surfaces can generally be expressed as

$$
q=\lambda \frac{\partial T}{\partial n}=f\left(q_{a}, q_{r}, q_{s}, q_{w}, q_{p}\right)
$$

where $n$ is the normal direction of the external surfaces and $q$ is the external heat flux, which is a combination of five components. These components were discussed in detail in Section 3.

The FE method, which is the most widely applied numerical tool in engineering fields, is selected as the numerical approach to solve the heat transfer problem of the arch dam in this study. The following equation can be obtained by finite element discretization of the governing equation:

$$
\begin{gathered}
\rho C_{p} \int_{V}[N]^{T}[N] d V\left\{\frac{\partial T}{\partial \tau}\right\}+\rho C_{p} \int_{V}\left[\frac{\partial N}{\partial x_{i}}\right]^{T} \lambda_{i j} \frac{\partial N}{\partial x_{j}} d V\{T\} \\
=\int_{V}[N]^{T} f d V+\int_{\Gamma}[N]^{T} q d \Gamma,
\end{gathered}
$$

in which $[N]$ denotes the interpolation function matrix; $\Gamma$ represents the external surface regions, which have various types.

\section{Case Study}

Project introduction was proposed in Section 2, and although the first impoundment of the reservoir started in March 2012, the dam now is still under construction. Obvious TRP occurred after sealing by measured data of various apparatus. Based on the aforementioned data analysis and research work on real thermal boundary conditions and with the help of a numerical analysis software [36], results of model calculation and verification are proposed in the current section.



FIGURE 6: Measured data of air temperature, wind speed, and water level process.

5.1. Calculation Conditions. Air temperature and wind speed of the dam site have been recorded since the beginning of the project by a local meteorological station, and the data are stored in a database. The water level of the reservoir has also been recorded since the upstream cofferdam was demolished on March 2012 (see Figure 6). A meteorological station is located near the dam site in Zhaotong, and the fundamental solar measurement data were used as the reference for the simulation. Air temperature in the galleries of the arc dam is not recorded, and as the galleries that are parallel to transversal section curve are long and airtight, respectively, air temperature is set as constant at $20^{\circ} \mathrm{C}$ which is equal to the mean annual temperature of the dam site.

Technical reports of the material experiments reveal that three main types of concrete are used in the dam construction. The material properties are listed in Table 1.

\subsection{Calculation Results and Discussions}

5.2.1. Verification. Temperature results of the numerical model must be calibrated with monitored data to verify correctness. The calculated temperature history of nodes that are near the positions of the embedded monitoring equipment are extracted by the program and compared with the monitored data. Both middle nodes which are at the center of the dam, and upstream (or downstream) nodes, which are underneath boundary surfaces of the arch dam, are shown in Figure 7. The calculated temperature and monitored data make a good agreement, which verifies the correctness of the numerical model. 


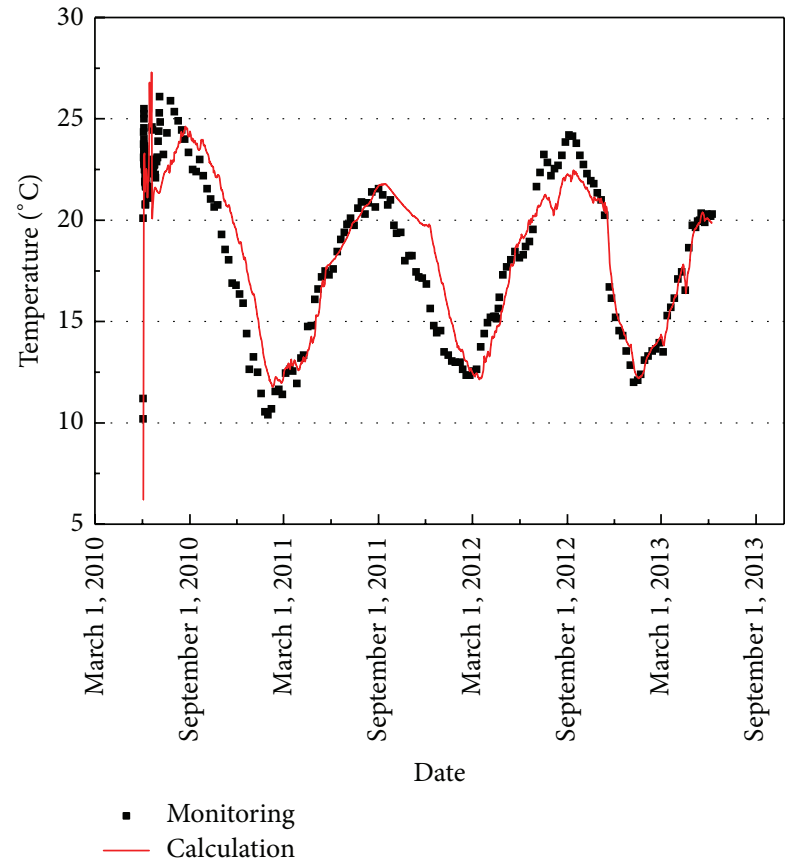

(a) $16 \#$ Section, elevation $=388.7$, near to downstream surfaces

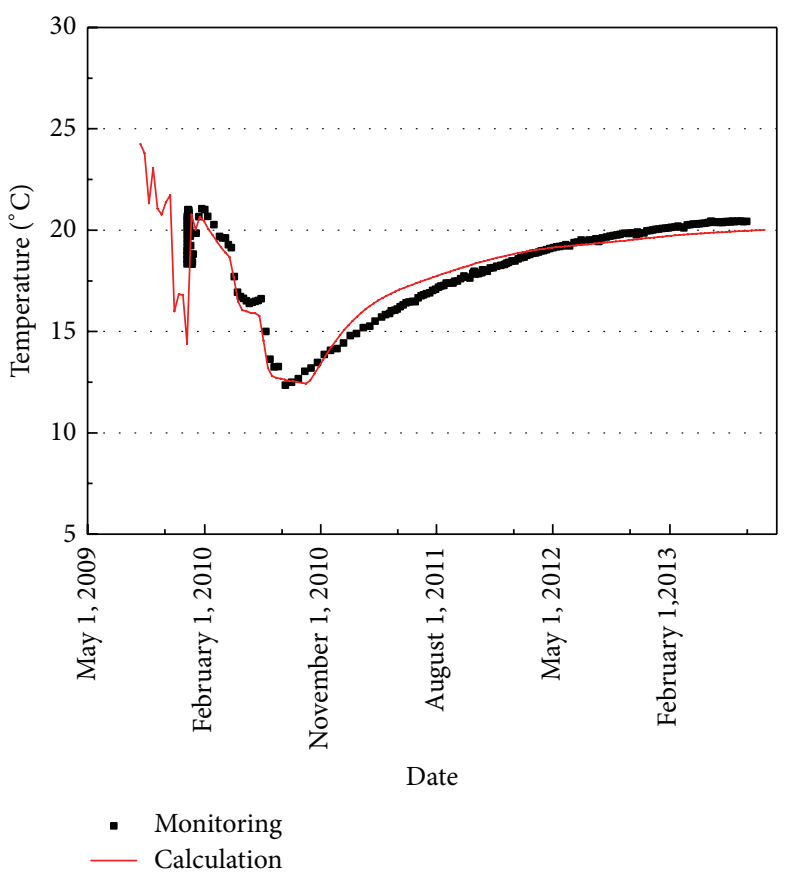

(b) $16 \#$ Section, elevation $=344.2$, center of concrete

FIGURE 7: Calculation results.

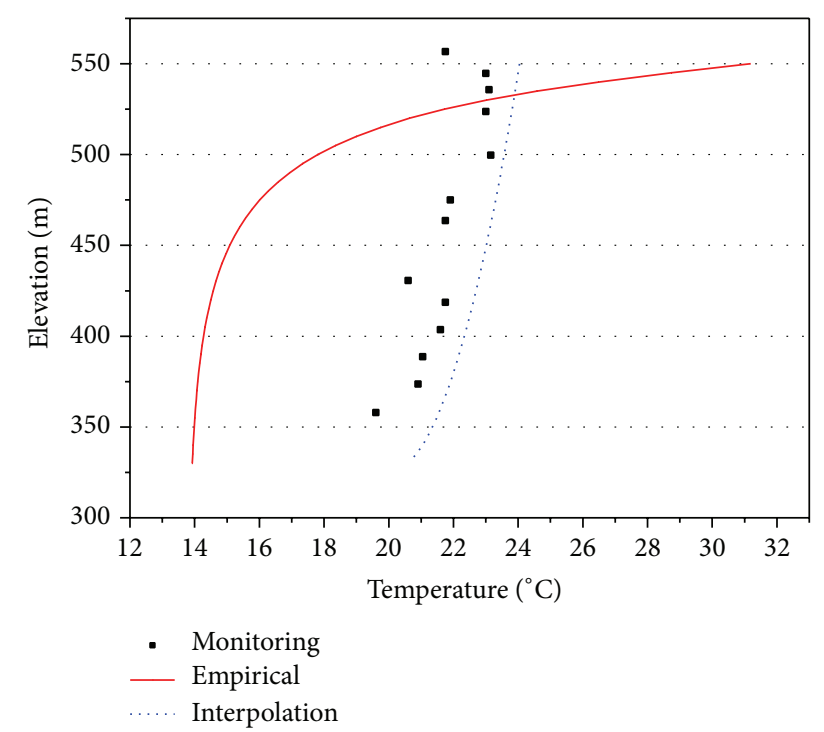

Figure 8: Calculated water temperature (date: 2013/06/25; water level $=550 \mathrm{~m})$.

As the impoundment started during the construction phase of the dam project, no thermometers were set in the reservoir to monitor the water temperature. Fortunately, several surface thermometers were embedded in concrete, which are approximately $0.1 \mathrm{~m}$ from the upstream surface, and the monitored data was recorded. The proposed interpolation, (8), in Section 3 is used to calculate water-side

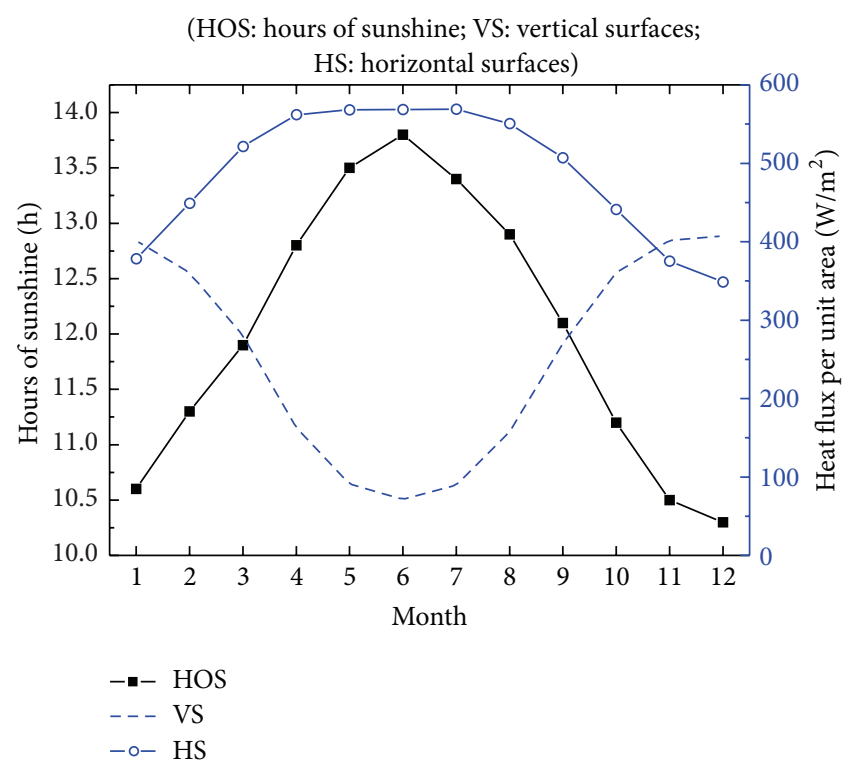

FIGURE 9: Calculated results of absorbed radiations from the sun.

boundary temperature $T_{w}$. Ground temperature $T_{g}$ is set to be constant at $25.6^{\circ} \mathrm{C}$ as monitored (see Figure 2(b)) and water temperature of the upper river $T_{r}$ is calculated by meteorological data. Calculated water temperature by interpolation method and empirical prediction method proposed in [25] are compared with the monitored data of surface thermometers (see Figure 8). The interpolation method is 


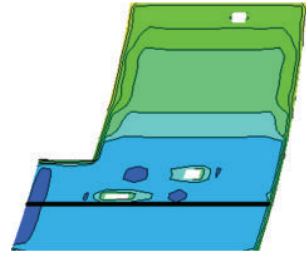

(a) August, 2010

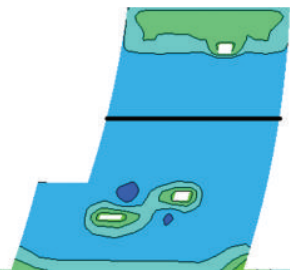

(b) January, 2011

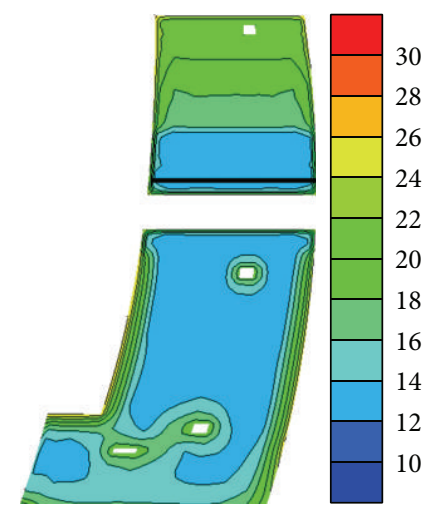

(c) August, 2011
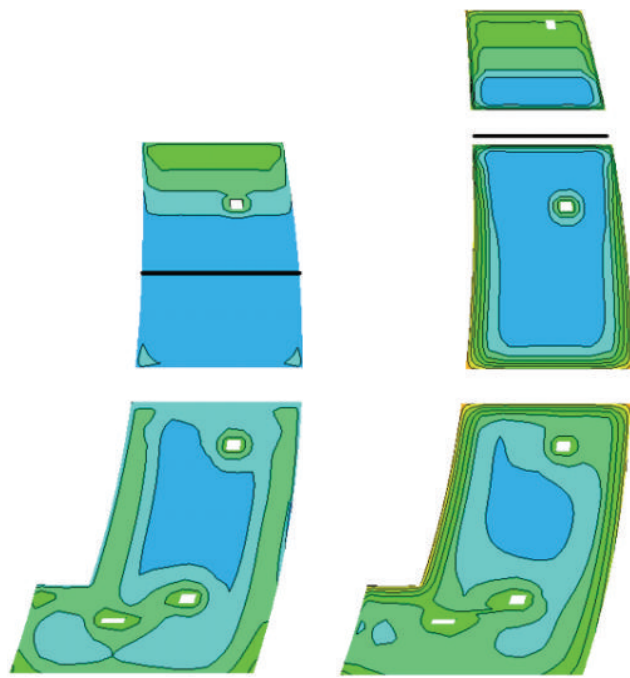

(d) January, 2012

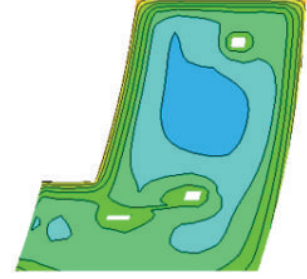

(e) August, 2012

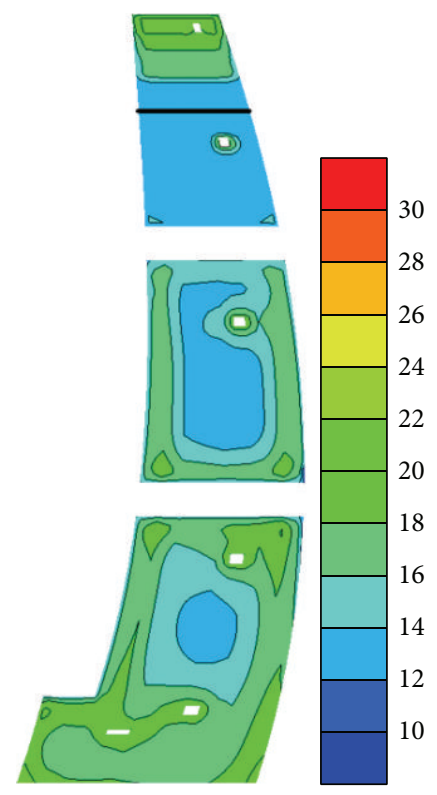

(f) January, 2013

FIGURE 10: Calculated temperature distributions of monolith 16.

considered more suitable to calculate water temperature of reservoir during its first impoundment period than the empirical method.

5.2.2. Calculation of Absorbed Radiations from Sun. As proposed in Section 1, solar irradiation has a significant impact on temperature distribution of the dam surface. This solar irradiation effect on the surface of the dam can be evaluated by heat flux per unit area. As the angles between sunlight and surfaces are different, the effect shows an obvious difference on horizontal and nonhorizontal surfaces of the arch dam. Meanwhile, hours between sunrise and sunset in summer are longer than in winter, differently affecting solar irradiation. The calculated results of absorbed radiations from the sun are shown in Figure 9. Absorbed radiations from the sun by horizontal surfaces in summer are quite large, reminding us that protection from sunshine for concrete surfaces in summer is reasonable and necessary.
5.2.3. Temperature Distribution. Figure 10 shows the temperature section of monolith 16 since the sealing of the first sealed region. The area beneath the black solid line in Figure 9 denotes the sealed regions. The following conclusions can be drawn from the temperature distributions.

(1) Boundary conditions have a significant impact on temperature distribution of the arch dam, especially under the boundary surfaces.

(2) The surface temperature gradient of the arch dam is larger in summer than in winter (see Figures 10(b), $10(\mathrm{c}), 10(\mathrm{e})$, and 10(f)), as the sealing temperature of the dam is $12^{\circ} \mathrm{C}$ to $13^{\circ} \mathrm{C}$, which is much lower than the average summer air temperature and close to the average winter air temperature.

(3) The galleries and outlet holes have obvious impact on the temperature distribution of the arch dam. As the air temperature in galleries is set to be constant 
TABLE 1: Material properties of dam concrete.

\begin{tabular}{lccc}
\hline Material property & Type I & Type II & Type III \\
\hline Basic heat transfer & & & \\
$\quad C_{p}\left(\mathrm{~J} / \mathrm{kg} \cdot{ }^{\circ} \mathrm{C}\right)$ & 943.0 & 934.0 & 860.0 \\
$\quad \rho\left(\mathrm{kg} / \mathrm{m}^{3}\right)$ & 2663 & 2663 & 2663 \\
$\quad \lambda\left(\mathrm{W} / \mathrm{m} \cdot{ }^{\circ} \mathrm{C}\right)$ & 2.14 & 2.14 & 2.14 \\
Hydration model & & & \\
$\quad \theta_{0}\left({ }^{\circ} \mathrm{C}\right)$ & 27.5 & 26.0 & 25.0 \\
$m_{1}$ & 0.3 & 0.3 & 0.252 \\
$m_{2}$ & 0.03 & 0.03 & 0.025 \\
$\quad s$ & 0.6 & 0.6 & 0.6 \\
Radiation & & & \\
$\quad e$ & 0.88 & 0.88 & 0.88 \\
Air-side convection & & & \\
$\quad a$ & 0.99 & 0.99 & 0.99 \\
$\quad b$ & 0.21 & 0.21 & 0.21 \\
$\quad m$ & 1.0 & 1.0 & 1.0 \\
Protection & & & \\
$\quad \lambda_{p}$ for quilt covers $\left(\mathrm{W} / \mathrm{m} \cdot{ }^{\circ} \mathrm{C}\right)$ & 0.045 & 0.045 & 0.045 \\
$\quad \lambda_{p}$ for PFP boards $\left(\mathrm{W} / \mathrm{m} \cdot{ }^{\circ} \mathrm{C}\right)$ & 0.036 & 0.036 & 0.036 \\
\hline
\end{tabular}

at $20^{\circ} \mathrm{C}$, larger than the sealing temperature, temperature gradient is generated in concrete close to the galleries after sealing as the sealing temperature is $12^{\circ} \mathrm{C}$ to $13^{\circ} \mathrm{C}$ (see Figures $10(\mathrm{~b})$ to $10(\mathrm{e})$ ). The surfaces of the outlet holes are in contact with the air, and temperature gradient is also generated under the surface (see Figure 10(e)).

(4) The ground temperature has impact on the temperature distribution of the arch dam. Measured temperature at $25.6^{\circ} \mathrm{C}$ in deep foundation is much higher than the sealing temperature of the arch dam and the concrete contacted to the foundation is kind of heated by the warmer foundation.

(5) Temperature in the internal concrete of after-sealed regions is gradually rising as the results of a higher outside temperature. The existence of galleries and outlet holes accelerate the process of temperature rise. With temperature rise in the internal concrete of the lower sealed regions, temperature gradient around the galleries decreases.

5.2.4. Calculated Temperature Rise after Sealing. Qualitative temperature rise can be found from the temperature distributions of the arch dam as previously proposed. To compare calculated temperature rise with measured data quantitatively, mean amplitudes of temperature rise in sealed regions are derived from simulation results and plotted in Figure 11, in which case 1 considers the existence of outlet holes and galleries of the arch dam but case 2 does not. The calculated amplitudes of temperature rise in case 1 and monitored data are shown to be in good agreement, which verifies our conjecture that the TRP occurs mainly because

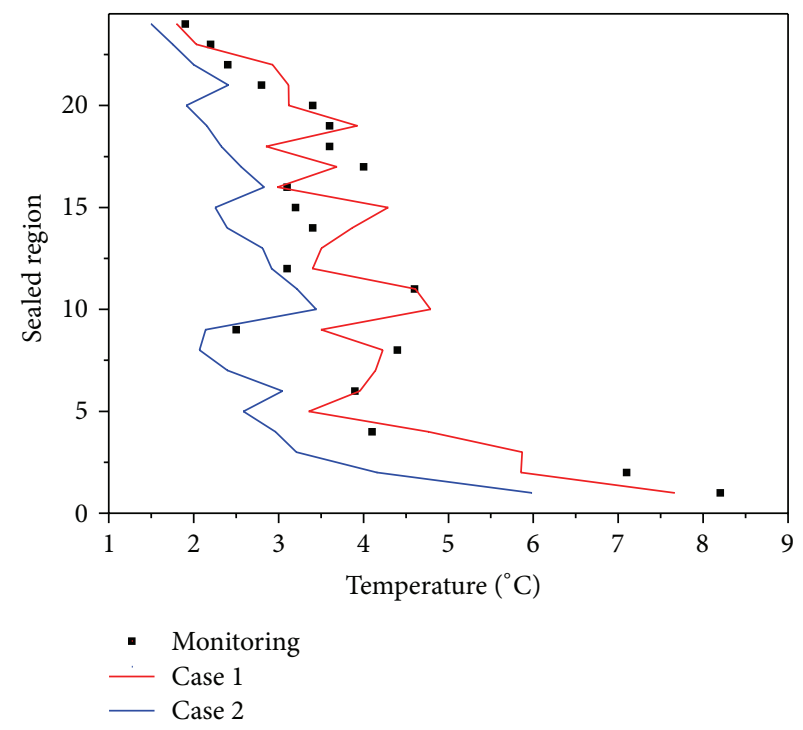

FIgURE 11: Calculated amplitudes of temperature rise.

the external temperature of the arch dam is higher than its sealing temperature. The mechanism of TRP occurring in the arch dam is explained in Figure 12. The temperature in the surface layer of the arch dam has seasonal variation along with air temperature of which the average annual value is approximately $20^{\circ} \mathrm{C}$, which is much higher than the sealing temperature. Meanwhile, the ground temperature and air temperature in galleries are constant at $25.6^{\circ} \mathrm{C}$ and $20^{\circ} \mathrm{C}$, respectively. An outer shell with higher average temperature than the sealing temperature develops and heats continuously the inner concrete of the arch dam, showing up as TRP.

\section{Conclusions}

Based on the measured temperature, a TRP is found to occur in the after-sealed regions of an arch dam. Temperature data recorded by various monitoring apparatus embedded in the arch dam are mined and analyzed in this study. Mathematical methods for different thermal boundary conditions of the arch dam, including external boundary conditions and internal heat source conditions, are proposed to simulate the real boundary conditions. A finite element model is implemented considering both the construction and operation phase of the arch dam. Results show good agreement with the measured temperature, which verifies the validity of the proposed method and also our conjecture that the TRP occurs mainly because the external temperature of the arch dam is higher than its sealing temperature. The mechanism of TRP occurring in the arch dam can be simply described as that an outer shell with higher average temperature than sealing temperature develops and continues heating the inner concrete of the arch dam. Galleries and outlet holes of the arch dam have obvious impacts on the temperature distribution of the dam, and these holes in the dam accelerate the process of temperature rise. As a prediction depends on the above analysis, the temperature in the after-sealed regions of the 


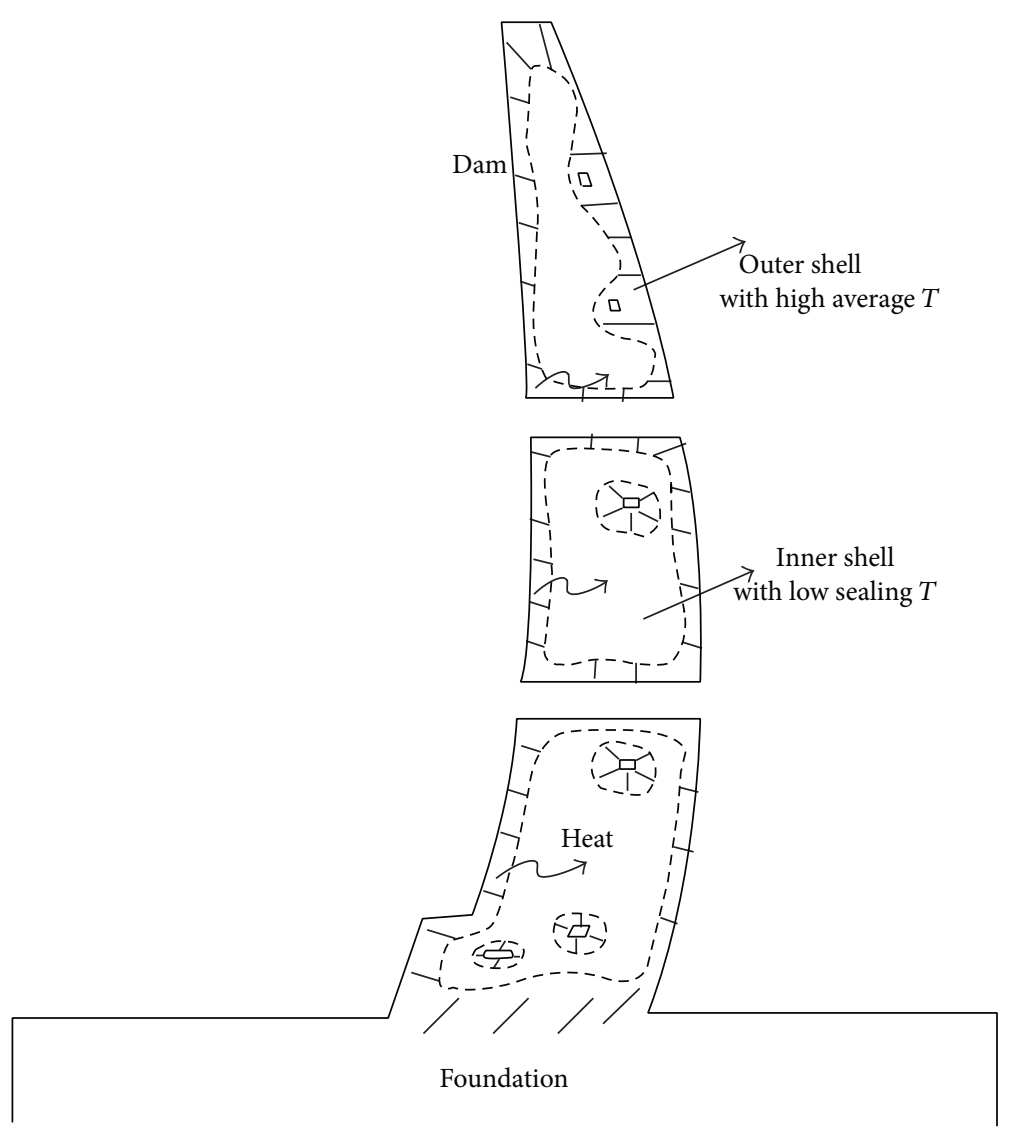

FIgURE 12: Explanation of TRP happens.

arch dam will continue rising before reaching the mean annual temperature of the external environment.

\section{Conflict of Interests}

The authors declare that they have no conflict of interests regarding the publication of this paper.

\section{Acknowledgments}

This work is supported by the National "973" Researching Project of China (no. 2013CB035902), Research Project of State Key Laboratory of Hydroscience and Engineering of Tsinghua University (no. 2012-KY-4), and National Nature Science Foundation of China (nos. 51279087 and 51339003).

\section{References}

[1] USACO Engineering, Arch dam design, chapter 8, pp. 1-15, 1994.

[2] F. Sheibany and M. Ghaemian, "Effects of environmental action on thermal stress analysis of Karaj concrete arch dam," Journal of Engineering Mechanics, vol. 132, no. 5, pp. 532-544, 2006.

[3] P. Leger, J. Venturelli, and S. S. Bhattacharkee, "Seasonal temperature and stress distributions in concrete gravity dams. Part 1: modelling," Canadian journal of civil engineering, vol. 20, no. 6, pp. 999-1017, 1993.
[4] P. Leger, J. Venturelli, and S. S. Bhattacharjee, "Seasonal temperature and stress distributions in concrete gravity dams. Part 2: behavior," Canadian journal of civil engineering, vol. 20, no. 6 , pp. 1018-1029, 1993.

[5] L. Agullo and A. Aguado, "Thermal behavior of concrete dams due to environmental actions," Dam Engineering, vol. 6, pp. 321, 1995.

[6] Z. Zhang and V. Garga, "State of temperature and thermal stress in mass concrete structures subjected to thermal shock," Dam Engineering, vol. 7, pp. 336-350, 1996.

[7] M. Daoud, N. Galanis, and G. Ballivy, "Calculation of the periodic temperature field in a concrete dam," Canadian Journal of Civil Engineering, vol. 24, no. 5, pp. 772-784, 1997.

[8] F. Jin, Z. Chen, J. Wang, and J. Yang, "Practical procedure for predicting non-uniform temperature on the exposed face of arch dams," Applied Thermal Engineering, vol. 30, no. 14-15, pp. 2146-2156, 2010.

[9] V. Kuzmanovic, L. Savic, and J. Stefanakos, "Long-term thermal two- and three-dimensional analysis of roller compacted concrete dams supported by monitoring verification," Canadian Journal of Civil Engineering, vol. 37, no. 4, pp. 600-610, 2010.

[10] C. Zhao, Dynamic and Transient Infinite Elements, Springer, Berlin, Germany, 2009.

[11] C. Zhao, "Computational simulation of wave propagation problems in infinite domains," Science China: Physics, Mechanics and Astronomy, vol. 53, no. 8, pp. 1397-1407, 2010.

[12] C. Zhao and S. Valliappan, "Mapped transient infinite elements for heat transfer problems in infinite media," Computer Methods 
in Applied Mechanics and Engineering, vol. 108, no. 1-2, pp. 119131, 1993.

[13] Y. Wu and R. Luna, "Numerical implementation of temperature and creep in mass concrete," Finite elements in analysis and design, vol. 37, no. 2, pp. 97-106, 2001.

[14] J. Yang, Y. Hu, Z. Zuo, F. Jin, and Q. Li, “Thermal analysis of mass concrete embedded with double-layer staggered heterogeneous cooling water pipes," Applied Thermal Engineering, vol. 35, no. 1, pp. 145-156, 2012.

[15] J. Palyvos, "A survey of wind convection coefficient correlations for building envelope energy systems' modeling," Applied Thermal Engineering, vol. 28, no. 8-9, pp. 801-808, 2008.

[16] Y. Lee, M. S. Choi, S. T. Yi, and J. K. Kim, "Experimental study on the convective heat transfer coefficient of early-age concrete," Cement and Concrete Composites, vol. 31, no. 1, pp. 60-71, 2009.

[17] R. Polivka and E. Wilson, "Finite element analyses of non-linear heat transfer problems," Report 76-2, UC SESM, 1976.

[18] R. Luna and Y. Wu, "Simulation of temperature and stress fields during RCC dam construction," Journal of Construction Engineering and Management, vol. 126, no. 5, pp. 381-388, 2000.

[19] ASHRAE, Fundamentals Volume., Ashrae Handbook Series, Publications Traffic Administrator, Atlanta, Ga, USA, 2009.

[20] Y. Hu, Z. Zuo, Q. Li et al., "Boolean-based surface procedure for the external heat transfer analysis of dams during construction," Mathematical Problems in Engineering, vol. 2013, Article ID 175616, 17 pages, 2013.

[21] NIST, The NIST Reference on Constants, Units, and Uncertainty, 2011.

[22] Y. Shiming and T. Wenquan, Heat Transfer, vol. 1, Higher Education Press, Beijing, China, 1998.

[23] W. S. Janna, Engineering Heat Transfer, CRC Press, New York, NY, USA, 2000.

[24] S. C. Chapra, Surface Water-Quality Modeling, vol. 1, McGrawHill, New York, NY, USA, 1997.

[25] B. Zhu, "Prediction of water temperature in reservoirs," Journal of Hydraulic Engineering, vol. 16, no. 2, pp. 12-21, 1985 (Chinese).

[26] D. Caissie, N. El-Jabi, and M. G. Satish, "Modelling of maximum daily water temperatures in a small stream using air temperatures," Journal of Hydrology, vol. 251, no. 1-2, pp. 14-28, 2001.

[27] C. Zhao, B. E. Hobbs, and A. Ord, Convective and Advective Heat Transfer in Geological Systems of Crustal Scales, Springer, Berlin, Germany, 2008.

[28] C. Zhao, H. B. Mühlhaus, and B. E. Hobbs, "Finite element analysis of steady-state natural convection problems in fluidsaturated porous media heated from below," International Journal for Numerical and Analytical Methods in Geomechanics, vol. 21, no. 12, pp. 863-881, 1997.

[29] C. Zhao, B. E. Hobbs, A. Ord, P. Hornby, P. Shenglin, and L. Liu, "Theoretical and numerical analyses of pore-fluid flow patterns around and within inclined large cracks and faults," Geophysical Journal International, vol. 166, no. 2, pp. 970-988, 2006.

[30] C. Zhao, B. E. Hobbs, A. Ord, S. Peng, and L. Liu, "Inverselymapped analytical solutions for flow patterns around and within inclined elliptic inclusions in fluid-saturated rocks," Mathematical Geosciences, vol. 40, no. 2, pp. 179-197, 2008.

[31] C. Zhao, B. E. Hobbs, H. B. Mühlhaus, A. Ord, and G. Lin, "Convective instability of 3-D fluid-saturated geological fault zones heated from below," Geophysical Journal International, vol. 155, no. 1, pp. 213-220, 2003.
[32] C. Zhao, B. E. Hobbs, A. Ord, S. Peng, H. B. Mühlhaus, and L. Liu, "Theoretical investigation of convective instability in inclined and fluid-saturated three-dimensional fault zones," Tectonophysics, vol. 387, no. 1-4, pp. 47-64, 2004.

[33] C. Zhao, B. E. Hobbs, and A. Ord, "Numerical Methods and Algorithms," in Fundamentals of Computational Geoscience, vol. 122 of Lecture Notes in Earth Sciences, pp. 1-6, Springer, Berlin, Germany, 2009.

[34] B. Zhu, "Equivalent equation of heat conduction in mass concrete considering the effect of pipe cooling," Journal of Hydraulic Engineering, vol. 22, no. 3, pp. 28-34, 1991 (Chinese).

[35] Z. Zuo, Y. Hu, Y. Duan, and J. Yang, "Simulation of the temperature field in mass concrete with double layers of cooling pipes during construction," Journal of Tsinghua University, vol. 52, no. 2, pp. 186-189, 2012 (Chinese).

[36] Z. Zuo, Y. Hu, Q. Li et al., "User-friendly thermal-stress coupled simulating platform of mass concrete," Chinese Journal of Computational Mechanics, vol. 30, no. 1, pp. 1-6, 2013 (Chinese). 


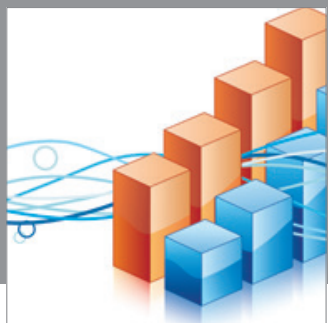

Advances in

Operations Research

mansans

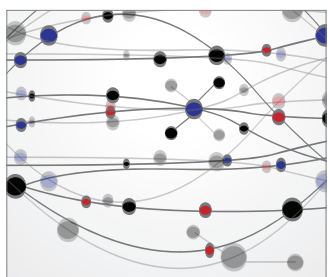

The Scientific World Journal
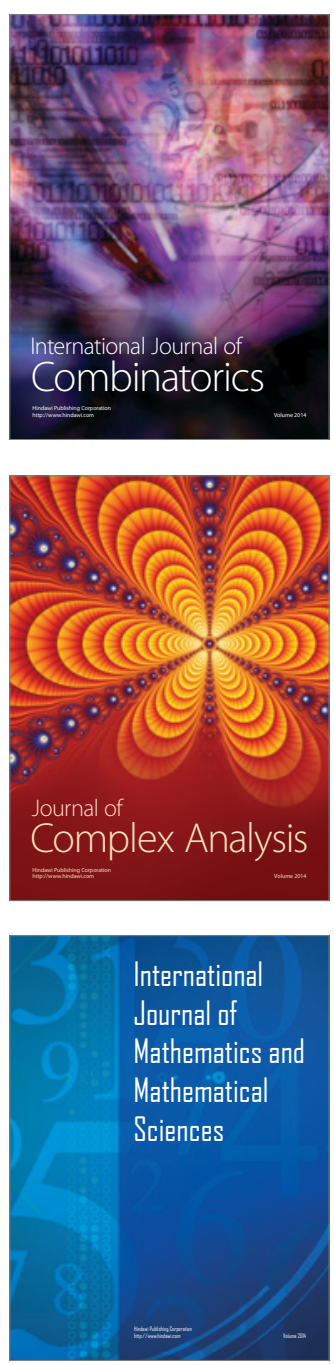
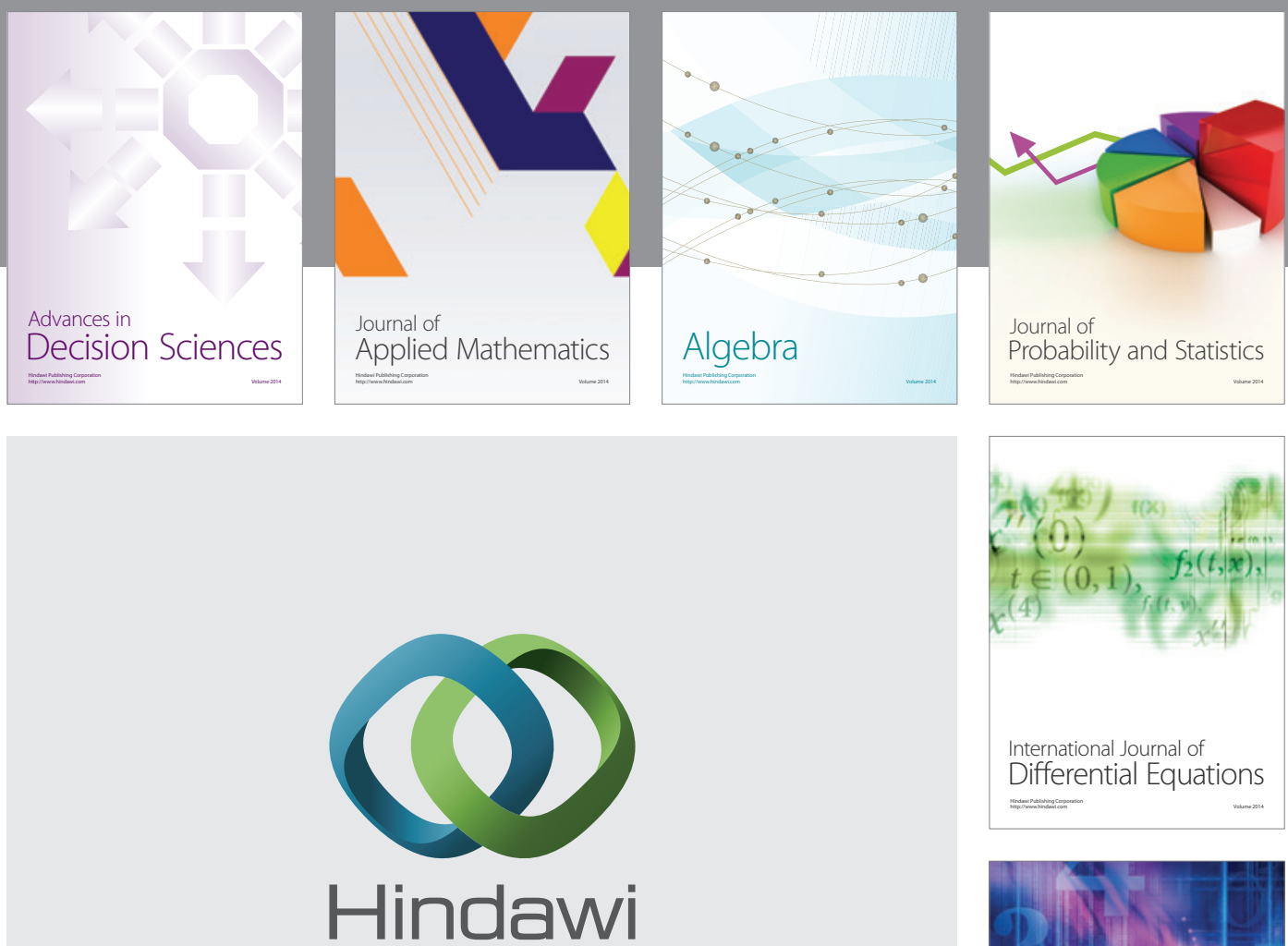

Submit your manuscripts at http://www.hindawi.com


Journal of

Function Spaces

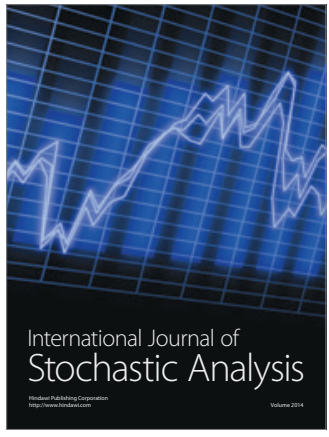


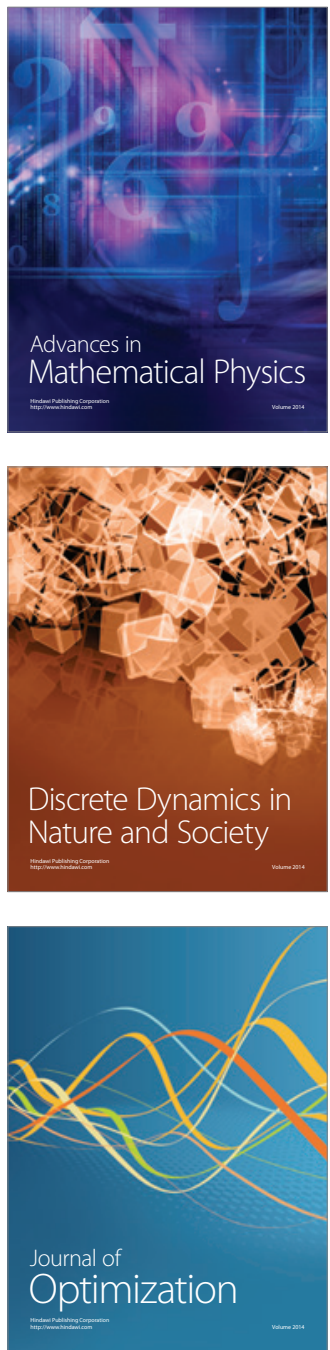